\title{
Concorrência tributária desleal: guerra fiscal entre os entes da Federação
}

\author{
Guilherme Luis Muramatsu Pereira ${ }^{1}$ \\ Profa. Dra. Marlene Kempfer Bassoli ${ }^{2}$
}

\begin{abstract}
Resumo
Constituem objetivos fundamentais da República Federativa brasileira a erradicação e marginalização da pobreza e a redução das desigualdades sociais e regionais (Art. 3o, III e Art. 170, VII, CF/88). É intrínseco ao pacto federativo, albergado em âmbito constitucional, a autonomia política, administrativa e financeira dos membrosfederados. No exercício de suas prerrogativas, poderão os governos federal, estadual e municipal concederem benefícios, na forma de incentivos fiscais, de forma a instigarem a economia local e o desenvolvimento sócio-econômico (Art. 151, I, CF/88). No Brasil, a possibilidade de intervenção estatal é uma proposta constitucional. A livre iniciativa mantém-se como princípio fundamental da ordem econômica (Art. 10, IV e 170, CF/88) e se ocupa em limitar essa atividade interventiva. A intervenção será sempre possível quando houver a necessidade de submeter atividades econômicas às regras constitucionais (Art. 170, CF/1988). Diante deste panorama, discute-se a possibilidade da concessão de incentivos fiscais pelos membros da federação para serem utilizados como instrumentos para a denominada "guerra fiscal" e, conseqüentemente, sua constitucionalidade ou não. Além deste aspecto traz-se à tona os reflexos desta intervenção, no caso incentivos, no domínio econômico; dentre eles o de afetar o regime jurídico-econômico constitucional, mais especificamente 0 desrespeito à livre concorrência.
\end{abstract}

Palavras-Chave: Federalismo fiscal; Guerra fiscal; Concorrência desleal; Uniformidade geográfica; Ações afirmativas; Políticas públicas de inclusão; Extrafiscalidade.

\section{Introdução}

O termo concorrência à luz da Economia evoca a idéia de mercado, um dos mecanismos pelo qual se satisfazem as necessidades coletivas, regulamenta-se a utilização dos fatores de produção, estabelece-se o crescimento econômico das sociedades e determina a distribuição dos rendimentos.

\footnotetext{
${ }^{1}$ Graduando no curso de Direito na Universidade Estadual de Londrina (UEL) e de Ciências Contábeis na Pontifícia Universidade Católica do Paraná (PUC-PR).

${ }^{2}$ Professora da Universidade Estadual de Londrina (UEL), PUC/PR-Londrina e UNIMAR/SP, com titulação de Mestrado e Doutorado em Direito do Estado pela Pontifícia Universidade Católica de São Paulo(PUC/SP) .
} 
A concorrência também se processa no campo de ação público-institucional e não apenas no terreno da atividade empresarial. Existe, particularmente, entre esferas dos governos estaduais e municipais. Nestes casos têm reflexos muito significantes no estabelecimento das condições de competitividade das empresas.

No que tange à tributação, a concorrência fiscal entre Estados-membros e entre Municípios não visa somente obtenção de maior arrecadação tributos e sim atrair investimentos privados uma vez que estes contribuem para o desenvolvimento sócioeconômico.

A concorrência tributária se dá quando o sistema fiscal de uma entidade governamental afeta o sistema fiscal de uma segunda, atingindo receitas fiscais desta última. É sobretudo um fenômeno inerente à coexistência de múltiplos sistemas fiscais que se comportam de maneira autônoma.

Tal ocorrência possui o condão de constranger Estados e M unicípios concorrentes a baixarem sua carga tributária, aumentarem a rigorosidade na administração da despesa e assegurarem uma melhoria de sua competitividade em relação aos demais. Em muitas ocasiões, permite a redução das desigualdades sócio-econômicas entre os entes federados.

Haverá ocasiões, entretanto, em que o fenômeno da concorrência tributária surtirá implicações prejudiciais na economia de um país. No contexto brasileiro, empreendem-se severas discussões tanto no plano dos efeitos econômicos quanto à constitucionalidade da concessão ou não de benefícios fiscais, as quais dão azo à guerra fiscal.

No plano internacional, costuma-se destacar duas situações que decorrem desta política econômico-financeira de outros Estados: paraísos fiscais (tax havens) e regimes fiscais preferenciais prejudiciais. Estas realidades inquietam diversas organismos internacionais: a Organização para a Cooperação do Desenvolvimento Econômico (OCDE); 0 Fundo Monetário Internacional (FMI); o Grupo dos Sete (G7); a Organização Mundial do Comércio (OMC); e, também, a União Européia. Um exemplo curioso é a recente condenação dos Estados Unidos da América por parte da OMC pela aplicação das foreign sales corporations. Consistia tal prática na redução da carga fiscal de empresas norteamericanas nas operações de exportação por meio de filiais estrangeiras fantasmas sediadas em paraísos fiscais. 
Tendo em vista os aspectos que o tema abarca, quais sejam o modelo federativo de Estado, a concorrência fiscal e os casos concretos que despontam nos Tribunais do país, eivados de interesses políticos e econômicos, reveste-se de relevância o tema ora abordado. Serão os efeitos decorrentes do pacto federativo do Estado brasileiro, o fenômeno concorrencial tributário entre seus Estados-membros e alguns casos concretos de notoriedade no meio acadêmico abordados nos tópicos que se iniciam a seguir.

\section{0 modelo federativo brasileiro}

Tendo-se em vista que a concessão dos incentivos por parte dos Estados-membros gera reflexos nas economias individuais de cada ente da Federação, é crescente a necessidade da revisão do pacto federativo do Estado brasileiro.

O surgimento do modelo de Estado Federal deu-se nos Estados Unidos da América. Havia, por todo o século XVII, no território que atualmente é conhecido como o norteamericano, uma unidade substancial de linguagem, religião e lei. Todos estes fatores constituíam uma grande união de coletividades vizinhas.

Após os Congressos Continentais Americanos de 1774 e 1775 e da proclamação da independência de 1776, as colônias norte-americanas se converteram em treze estados, independentes de qualquer supremacia real e também independentes entre si. Foi somente ao final do século XVII que foi delimitado um novo regime oriundo das necessidades próprias daquele povo.

Buscavam os Estados norte-americanos uma forma de governo intermediária entre a absoluta independência e a completa fusão destes em um novo Estado. Os constituintes como bem destaca o jurista Oswaldo Aranha Bandeira de M ello (1948, p. 14) - receosos de excessos de poder advindos da União, assim como para evitar possível prepotência de alguns dos membros mais fracos, conceberam um sistema de pesos e contrapesos dotados de duas características fundamentais: repartição das competências e não de sua soberania, entre 0 governo nacional e os governos locais por via de rigidez constitucional e interferência direta e indireta dos Estados nas deliberações da União.

Desse expediente nasce uma nova forma de Estado, ocupando um plano intermediário entre a confederação de Estados e 0 Estado unitário e o que recebeu o nome de Estado federal. 
O princípio federativo esteve continuamente presente na trajetória da políticojurídica brasileira, com períodos de maior e menor centralização. Após a promulgação da Constituição Republicana de 1891, que legitimou a famosa política do 'café com leite', o Brasil adotou a forma federativa de Estado. Províncias foram transformadas em Estadosmembros e estes passaram a gozar de relativa autonomia em relação ao governo central.

"Autonomia se conceitua como a faculdade de uma comunidade jurídica em regular seus próprios negócios, mediante normas jurídicas por ela própria editadas" (M ELLO, 1948, p. 46). Significa governo próprio. Toda coletividade é autônoma quando, dentro do círculo pré-fixado pela coletividade superior, tem a capacidade de provimento próprio dos cargos governamentais e a faculdade de organização própria dos assuntos que Ihe forem delegados como do seu peculiar interesse. Em federações os Estados-membros interferem sempre nas deliberações da União, enquanto os Estados denominados Unitários, não.

Após a promulgação da Carta de 1988, os Estados voltaram a gozar de autonomia política, administrativa e financeira, e puderam, enfim, eleger seus respectivos deputados e senadores. Foram contemplados Estados e Municípios com maior liberdade de tomada de decisões, tanto políticas quanto econômicas. Este processo corroborou para o surgimento de um conflito entre estes membros em razão da descentralização fiscal e política, iniciada no final dos anos 70 .

Entende-se como Estado Federal o próprio governo central, a União dos Estadosmembros. Ela é responsável pela segurança nacional, pela diplomacia e pela representação internacional de cada Estado, visto que é detentor dos poderes de representação de soberania da federação. Em relação a algumas matérias é defeso a qualquer outro membro da federação legislar a não ser a União.

0 federalismo brasileiro baseia-se na cooperação. Conforme pode-se depreender do parágrafo único do Art. 23 da Constituição:

\footnotetext{
Art. 23.....

Parágrafo único - Leis complementares fixarão normas para a cooperação entre a União e os Estados, o Distrito Federal e os Municípios, tendo em vista o equilíbrio do desenvolvimento e do bem-estar em âmbito nacional." [grifo não consta no original].
} 
Resta consagrado, portanto, o federalismo de cooperação visando o equilíbrio do desenvolvimento e do bem-estar em recinto constitucional.

Para a redução da pressão fiscal, é incontestável a importância da existência de uma certa competitividade entre os Estados, o que serve como estímulo para o emprego mais eficiente da receita pública, otimizando seus orçamentos e serviços públicos. Tixier (1986, p. 30) enuncia em respeitável lição que há somente paraísos fiscais porque existem infernos fiscais e esta concorrência poderá se prestar para reduzir o que houver de atormentador nos sistemas tributários vigentes, bem como gerar aperfeiçoamentos qualitativos nos atos de arrecadação, fiscalização e administração dos tributos.

A competição degenera-se em predatismo quando a mesma passa a acarretar prejuízos para a União e para os Estados-membros. Ocorre, v. g., quando Estados passam a conceder incentivos fiscais para captar investimentos sem considerar os reflexos dessa atitude na economia nacional, sem ao menos respeitar a finalidade social de uma lei sopesada em um contexto sócio-econômico brasileiro em que as discrepâncias regionais são tão gritantes.

Vale ressaltar, por fim, que uma demasiada autonomia dos entes federados tende a aproximar o Estado para o modelo de uma confederação e a forte centralização tende a evoluir o modelo para um Estado Unitário. 0 grande desafio é o de se encontrar, assim como em muitas outras áreas do conhecimento, um ponto de equilíbrio, entre autonomia legislativa e restrições que a ela evitem a desconfiguração do pacto federativo, albergado pela Constituição Federal.

\section{Intervenção no domínio econômico e a Constituição Federal de 1988}

Um Estado Liberal, como entidade separada da sociedade civil, somente intervém juridicamente nesta em setores limitados e em caráter excepcional, o que se dá normalmente por meio de normas penais e tributárias (NOVOA, 2000, p. 95).

Seriam a expressão de um ordenamento jurídico limitador da autonomia privada, frente a um Direito Civil regulador da liberdade e da propriedade dos cidadãos. Por

\footnotetext{
3 "La norma tributaria sólo podía ser entendida desde estos puntos de vista cuando la supuesta excepcionalidad fuera la excepcionalidad propia del Estado liberal; un Estado como entidad separada de la sociedad civil, que sólo intervendría jurídicamente en ésta 'en sectores limitados y excepcionales', normalmente a través de normas penales y tributarias ".
} 
conseguinte, normas tributárias e penais seriam normas extraordinárias, em uma ordinariedade baseada na não-intervenção, cujo âmbito natural seria o Direito Civil, qualificado como marco jurídico de uma atividade essencialmente livre.

0 tributo incide sobre feitos de natureza econômica, cujo acontecimento tem lugar no mercado, no qual perdura a máxima do direito ao lucro ou, o que é o mesmo, à apropriação para a utilidade privada dos resultados de êxito pessoal, de modo a haver a possibilidade de se falar em uma esfera privada aquisitiva - Erwebssphäre - que é objeto de intervenção natural pelo poder impositivo (NOVOA, 2000, p. 98) 4

Quanto à possibilidade de concessão de incentivos a empresas privadas, tal hipótese é viável ante os Artigos 170 e 174 da Lei M aior, assim como pelos seus Arts. $1^{0}$, III e IV e $3^{0}$, II e III, que confirmam a orientação aos governos na promoção da dignidade da pessoa humana, dos valores sociais do trabalho, da livre iniciativa e pelos objetivos fundamentais da República. A efetividade destes dispositivos possibilita garantir 0 desenvolvimento nacional, a erradicação da pobreza e a marginalização e redução das desigualdades sociais e regionais.

No Art. 174 da Magna Carta está delineado:

Art. 174 - Como agente normativo e regulador da atividade econômica, o Estado exercerá, na forma da lei, as funções de fiscalização, incentivo e planejamento, sendo este determinante para o setor público e indicativo para o setor privado [grifo não consta no original].

Em sentido semelhante, o Art. 151, I, estabelece que é admissível a concessão de incentivos fiscais destinados a "promover o equilíbrio do desenvolvimento econômico entre as diferentes regiões do país".

Pode-se compreender os incentivos como uma reação à crise temporária de determinado setor da economia, sendo sua função primeira a compensação das perdas e estimular a sobrevivência dos agentes na atividade (LOSS, 2002, p. 138). Essa linha de pensamento está em consonância com o fundamento da atuação do Estado no mercado,

\footnotetext{
4 “(...) el tributo incide sobre hechos de naturaleza econômica, cuyo acaecimiento tiene lugar en El mercado, el cual ensalza la máxima del derecho al lucro, o lo que es lo mismo, a la apropiación - Erwebsrecht - para la utilidad privada de los resultados del éxito personal, de modo que se ha podido hablar de una 'esfera privada adquisitiva' - Erwebssphäre - que es objeto natural de intervención por el poder impositivo".
} 
conforme se pode aduzir dos Artigos 218 e 219 da Constituição, que versam sobre a Ordem Social da Constituição (Titulo VIII):

Art. 218 - O Estado promoverá e incentivará o desenvolvimento científico, a pesquisa e a capacitação tecnológicas.

Art. 219 - 0 mercado interno integra o patrimônio nacional e será incentivado de modo a viabilizar o desenvolvimento cultural e sócio-econômico, o bem-estar da população e a autonomia tecnológica do País, nos termos de lei federal [grifo não se encontra no original].

É possível considerar como fundamento básico da atuação estatal no domínio econômico, não somente o Art. 170 da Lei Maior, contido no Título da Ordem Econômica e Financeira, mas, sim, nos Artigos 218 e 219; ante a consideração do mercado interno como parte integrante do patrimônio nacional.

Economicamente, a empresa beneficiada por incentivos de um determinado Estado-membro obtém vantagem sobre os concorrentes tendo em vista que sua curva de oferta é deslocada para baixo em relação às demais. Daí se abstrai a relação entre o princípio da livre concorrência e a concessão de incentivos estaduais, já que o incentivo relaciona-se diretamente à formação de preços, matéria intrinsecamente ligada à concorrência (LOSS, 2002, p. 141).

No $\S 4^{0}$ do Artigo 173 da Constituição vigente está enunciado: “A lei reprimirá o abuso do poder econômico que vise à dominação dos mercados, à eliminação da concorrência e ao aumento arbitrário dos lucros" [original sem grifo]. Conformam-se os três desvios que devem ser evitados, por ferir a ética empresarial na exploração da atividade econômica.

A Economia tem os seus próprios caminhos, mas não só o Estado deve respeitá-los, abstendo-se de criar obstáculos contrários aos interesses da sociedade e de forma confiscatória ou injusta, como também os próprios agentes econômicos não podem maltratar as normas da livre concorrência, praticando atitudes abusivas.

A livre-iniciativa constitui-se no direito de acesso ao mercado, assegurando-se a todos os agentes econômicos a liberdade de escolha de atividade que desejam exercer, bem como 0 modo em que desejam exercê-la. 0 Art. 174 dá ênfase ao aspecto regulador e normativo do Estado na economia, enquanto garantidor da livre concorrência. É por meio 
desta intervenção indireta na atividade econômica que se assegura o direito à livre iniciativa, com a referida garantia à livre concorrência, como condicionante para 0 não comprometimento da liberdade de comércio e da indústria e o regular funcionamento dos mercados e da exploração dos meios de produção. A livre concorrência é, pois, "manifestação da livre iniciativa" (LOSS, 2002, p. 142).

A Constituição acolhe 0 intervencionismo econômico, entretanto, repudia 0 dirigismo. Não se subsume à doutrina liberal de Adam Smith e nem ao intervencionismo eminentemente keynesianista. Pode-se afirmar que a Constituição é capitalista, no entanto, a liberdade apenas é "admitida enquanto exercida no interesse da justiça social e confere prioridade aos valores da economia de mercado" (DA SILVA, 2001, p. 232).0 ímpeto constitucional não é a defesa do concorrente mas, sim, da concorrência e de todos os benefícios que são advindos à coletividade.

\section{Guerra fiscal}

Dá-se o que é denominado de Guerra Fiscal quando os Estados ou Municípios, visando atrair investimentos ao seu território, concedem benefícios à iniciativa privadas. Estes podem se manifestar na forma de benefícios fiscais, financeiros, financeiro-fiscais e/ou de infra-estrutura para as empresas voluntárias a serem transferidas ou a investir no território do Estado ou Município concedente.

Incentivos são, antes de tudo, instrumentos por meio do qual o Estado realiza determinados objetivos, estimulando ou desestimulando determinados ramos da atividade econômica. É a mais pura e relevante (Cretella Júnior [CRETELLA JÚNIOR, 1993, p. 4.047] emprega o termo "moderada“) demonstração de intervenção estatal na economia em um modelo capitalista. Podem ou não possuir natureza fiscal. Não possuirá tal característica, v. g., nos casos de doações de áreas a empresas para exploração de atividades. Haverá caráter fiscal quando recorre à isenção de tributos, redução de alíquotas, restrição da base de cálculo, técnica do diferimento e outros.

Com o fim de atrair melhores investimentos e para concentrar a maior quantidade de riqueza possível dentro de suas fronteiras, os entes federados, por vezes, elaboraram um verdadeiro planejamento tributário público construído não para obter, mas para favorecer a 
economia dos próprios tributos que cobra e desta forma reduzir a carga tributária ou fomentar operações isoladas.

Essa prática não é fato recente na política brasileira. Há registros que datam desde a década de $20^{5}$, mas nada comparado às proporções tomadas no decorrer da década de 90 .

É medida de iniciativa do Poder Executivo fundada na Constituição Federal, excluise total ou parcialmente o crédito tributário em que é detentor o poder público em prol do desenvolvimento de região ou setor relevante à coletividade. Pode ser compreendido, assim sendo, como norma jurídica de direção econômica a serviço do desenvolvimento que interesse ao país ou determinada região ou setor da economia (TRAM ONTIN, 2002, p. 111).

Deve-se constar, sempre, a indicação dos beneficiários, finalidade da concessão, condições para sua fruição, o prazo da vigência e o montante dos benefícios concedidos. Além disso, a indispensável necessidade de que se faça uma fiscalização adequada por parte do Poder Público a averiguar a efetiva aplicação dos recursos assim como o fortalecimento da economia local.

A Lei de Defesa da Concorrência, Lei n. 8.884/94, em seu Art. $7^{0}, \mathrm{XVIII}$, confere competência ao CADE - Conselho Administrativo de Defesa Econômica - a "instruir o público sobre as formas de infração da ordem econômica". A lesão da livre concorrência e da livre iniciativa constituem infrações contra a ordem econômica. Por essa razão, o Art. 20 da supra-citada lei adverte:

Art. 20 - Constituem infração da ordem econômica, independentemente de culpa, os atos sob qualquer forma manifestados, que tenham por objeto ou possam produzir os seguintes efeitos, ainda que não sejam alcançados:

I - limitar, falsear ou de qualquer forma prejudicar a livre concorrência ou a livre iniciativa; [grifo do autor]

Considerando-se que a Lei de n. 8.884/94 é aplicável a todas pessoas físicas ou jurídicas de direito público ou privado ${ }^{6}$, entes públicos e privados devem respeito aos seus preceitos, sendo perfeitamente razoável a possibilidade de apreço por parte do Conselho

\footnotetext{
${ }^{5}$ Em 1923 houve a criação do Imposto Sobre Vendas de Mercadorias (IVM), o qual em 1934 foi transformado no Imposto Sobre Vendas em Consignações (IVC). As próprias leis que os instituíram permitiam a disputa tributária entre as unidades federativas. Neste período, os Estados detinham autonomia sobre os referidos impostos na exportação e concediam reduções nas alíquotas para exportadores instalados em seu território, gerando variações nas alíquotas e, conseqüentemente, desigualdades tarifárias no sistema de cobranças.

${ }^{6}$ Arts. 15 e 23, III da Lei n. 8.884/94.
} 
dos incentivos provenientes de entes públicos como infrações à ordem econômica (LOSS, 2002, p. 154).

Em seus estudos contidos na publicação do perfil dos Municípios brasileiros em 2006, o Instituto Brasileiro de Geografia e Estatística - IBGE (2007, p. 26) informa que 49,5\% dos Municípios no país utilizam alguma espécie de incentivo para atrair investimentos privados. Em cidades grandes com mais de 500 mil habitantes esse percentual chega a $86 \%$. Dos anos 2004 a 2006, os benefícios mais utilizados foram a doação e a cessão de terrenos, seguidos do abatimento e/ ou isenção pura e simples de impostos e taxas (IBGE, 2007, p. 28).

Concessões por vezes acabam discriminando empresas não beneficiadas e que atuam no mesmo setor da economia, apesar de se encontrarem em condições muito semelhantes. Logo, a atuação do poder público acaba resultando em um desestímulo para a grande maioria que não é beneficiada pelas concessões. É um tratamento desigual entre contribuintes em situações equivalentes.

A análise da distribuição das cidades pelo mapa brasileiro no cartograma abaixo permite verificar que em alguns Estados a prática de favorecimento é mais presente do que em outros (IBGE, 2007, p. 25). As regiões Sul e Sudeste representam, juntas, $62,0 \%$ dos Municípios que abrem mão de arrecadar alguns tributos de forma a obterem uma contrapartida de outra maneira, em especial com geração de empregos e de renda. Santa Catarina e Rio Grande do Sul, por exemplo, figuram como unidades federativas com grande aglomeração de M unicípios vizinhos que adotam tais práticas. 


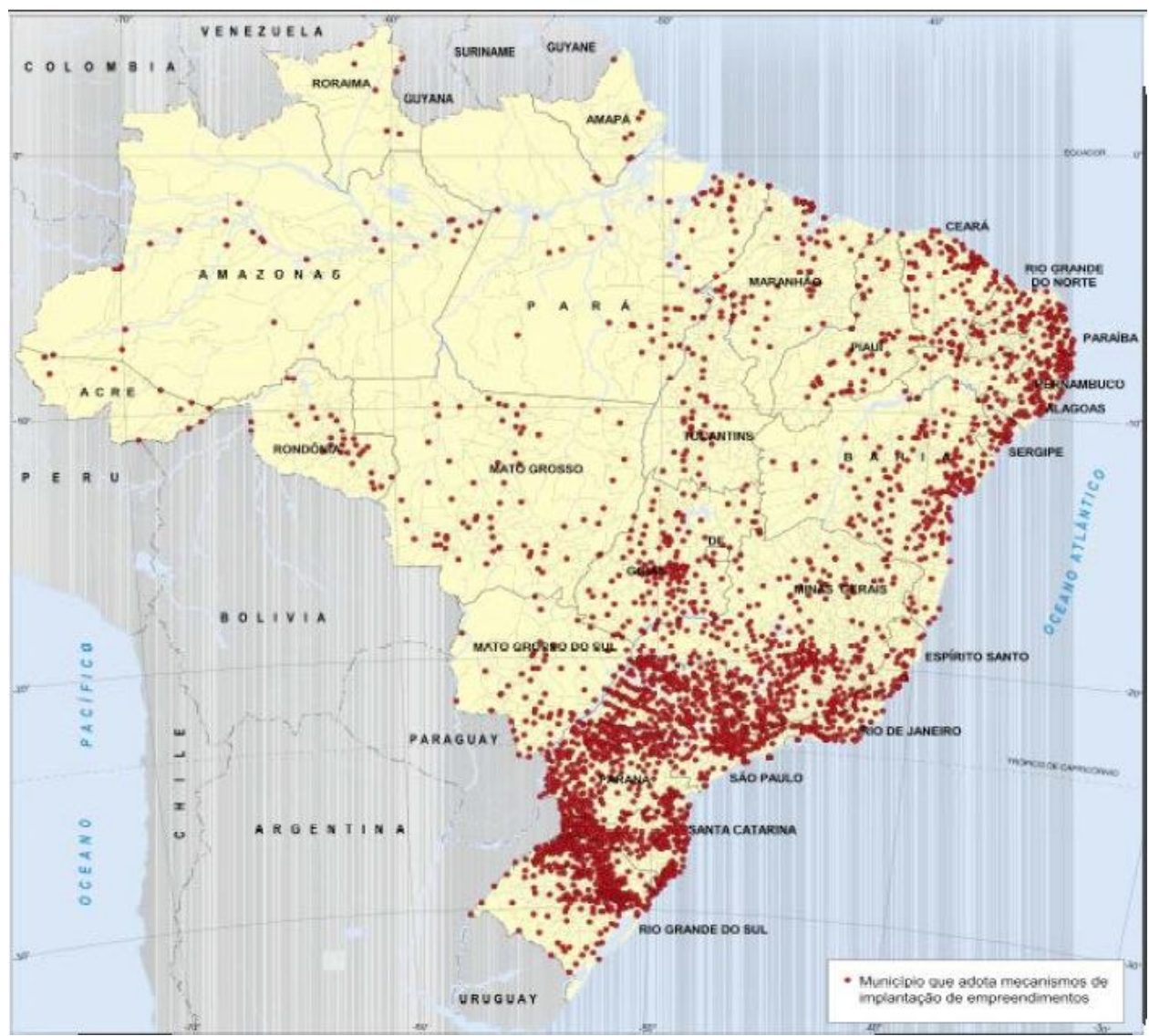

Cartograma 1 - M unicípios que adotam mecanismos de empreendimentos - Brasil - 2006.

Fonte: IBGE, Diretoria de Pesquisas, Coordenação da População e Indicadores Sociais; IBGE, Diretoria de Geociências, Coordenação de Geografia.

É a inteligência do Art. 155, $\S 2^{\circ}$, XII, g) da CF/88 o cabimento à Lei Complementar para regular a forma como serão concedidas e revogadas isenções, incentivos e benefícios fiscais, "mediante deliberação dos Estados e do Distrito Federal". Os Estados devem desenvolver suas políticas fiscais subordinando-as ao Conselho Nacional de Política Fazendária - CONFAZ, instituída pela Lei Complementar de n. 24/1975, que é o órgão harmonizador e que possui a finalidade precípua de estabelecer igualdade na política tributária.

A referida Lei foi recepcionada pela Constituinte de 1988 e veda qualquer espécie de isenção ou outra forma de incentivo relacionados ao ICM, a não ser que estes sejam resultado de ratificação de convênios celebrados pelos entes da federação. 0 ICMS possui um caráter notadamente nacional. É corolário da própria natureza de incidir sobre a circulação de mercadorias. Em conformidade com o conceito de federalismo de cooperação, 
não podem os Estados agirem solitariamente no que tange à sua exoneração fiscal, sob pena de rompimento do pacto federativo. O ICMS repercute na economia de todos os entes da federação.

Há sanções previstas para aqueles que afrontarem as disposições legais da Lei Complementar ${ }^{7}$. A legalidade dos incentivos ficou, portanto, vinculada ao crivo do órgão instituído pela Lei.

Há celeuma no que se refere à necessidade de convênio prévio dentre os membros federativos para a cessão de incentivos financeiros. 0 que é financeiro, relaciona-se às finanças e às instituições financeiras. 0 que é fiscal está ligado à arrecadação de caráter compulsório ao Estado, o "comportamento humano consistente em levar dinheiro aos cofres públicos" (ATALIBA, 2001, p. 23). Distinguem-se os incentivos puramente financeiros dos financeiro-fiscais. Estes consistem na devolução do tributo por meio de atividade financeira, devendo estar diretamente relacionado à arrecadação do tributo, ao financiamento, por meio de uma triangulação, utilizando-se de um fundo fiscal (LOSS, 2002, p. 149).

Incentivos puramente financeiros possuem dotações orçamentárias próprias. Não possuem a relação direta com o imposto recolhido pelo contribuinte e, conseqüentemente, não se relacionam diretamente à atividade tributária.

\section{Considerações sobre o caso FUNDAP/ ES e a Zona Franca/AM}

Alguns embates frutescências do fenômeno da guerra fiscal repercutem no meio doutrinário e jurisprudencial compondo importante contribuição neste estudo. É o caso do FUNDAP no Espírito Santo - Fundo para o Desenvolvimento das Atividades Portuárias - não se tratando de benefício fiscal, mas de fomento financeiro ${ }^{8}$. Portanto, não se rege pelo que está disposto no Art. 155, $\S 2^{\circ}$, XII, g da CF/88 e pela LC 24/75, já que um de seus requisitos prévios é a quitação do tributo.

\footnotetext{
${ }^{7}$ O Art. 80, parágrafo único da LC 24/75 assim enuncia: “Às sanções previstas neste artigo poder-se-ão acrescer a presunção de irregularidade das contas correspondentes ao exercício, a juízo do Tribunal de Contas da União, e a suspensão do pagamento das quotas referentes ao Fundo de Participação, ao Fundo Especial e aos impostos referidos nos itens VIII e IX, do Artigo 21 da Constituição Federal".

${ }^{8}$ Incentivo concedido pelo Governo do Estado do Espírito Santo para as empresas de exportação e importação que lá se estabelecem (Lei Estadual n. 2.508/1970).
} 
Considerando-se 0 fato de que incentivos financeiros, fiscais e financeiro-fiscais possuem efeitos semelhantes no mercado, influenciando na formação do preço dos produtos e, por conseqüência, na concorrência, entende-se que o CADE é o ente da administração pública competente, conforme o que está previsto legalmente, também para os incentivos financeiros (LOSS, 2002, p. 155).

O governo capixaba argumenta que não há qualquer interferência na relação jurídica tributária, regularmente constituída e extinta, cujos pressupostos constitucionais e legais são perfeitamente atendidos e 0 valor entregue pelo Estado é financiado, não se tratando de doação, mas de quantia que deverá ser devolvida pela empresa no tempo e modo acordados. É, portanto, "perfeitamente compatível com o regime jurídico do ICM, não configurando benefício de natureza fiscal, nem financeiro-fiscal, por isso não sujeitos à aprovação do CONFAZ, mediante edição de convênio, nos termos da Lei Complementar n. 24/75" (LOSS, 2002, p. 150).

Em contrapartida, há aqueles que sustentam (como o do governo do Estado de São Paulo) a inadmissibilidade dos benefícios financeiros. Sob o aspecto finalístico, caracterizaria "afronta ao sentido da vedação constitucional" (PEIXOTO, 2005, p. 1.096).

É um embate de difícil resolução. 0 disposto na Constituição Federal sobre o tema (Art. 155, $\S 2^{\circ}$, XII, g) limita-se ao aspecto tributário, referindo-se à questão financeira em capítulo diverso (Art. 163 e seguintes). Vale ressaltar que quando empresas instalam seus escritórios em Vitória/ES, sem ali fazer a operação de importação, somente efetuando a operação de troca de documentos fiscais, nada mais é que uma remessa simbólica de mercadorias, visto que fisicamente a circulação se dá em Estado diverso.

É em razão dessa simulação do critério territorial de incidência do ICM por meio do FUNDAP que 0 Governo do Estado de São Paulo, como retaliação direta à prática, editou 0 Comunicado Administrativo Tributário - CAT - de n. 36 em 29 de julho de 2004.

o Comunicado possui o propósito de esclarecer sobre a impossibilidade de "aproveitamento dos créditos de ICM S provenientes de operações ou prestações amparadas por benefícios fiscais de ICMS não autorizados por convênio celebrados nos termos da Lei Complementar n. 24, de 7 de janeiro de 1975".

Para fundamentar a validade de tal ato, invoca-se o princípio da não-cumulatividade (Art. 155, § 2 I, CF/88); o cabimento da Lei Complementar à ocasião de celebração de 
convênios em razão dos benefícios fiscais concedidos (Art. 155, § $2^{0}, X I I, g$ ), CF/88); e 0 princípio da livre concorrência (Art. 170, IV, CF/88) já que incentivos fiscais de outros Estados instituídos à revelia do convênio criam situação de desigualdade concorrencial entre o mercado local e aqueles situados fora do estado de São Paulo.

O Art. $1^{0}$ da Lei Complementar de n. 24/1975 preceitua:

\begin{abstract}
Art. 10.
Parágrafo único - 0 disposto neste artigo também se aplica:

I - à redução da base de cálculo;

II - à devolução total ou parcial, direta ou indireta, condicionada ou não, do tributo, ao contribuinte, a responsável ou a terceiros;

III - à concessão de créditos presumidos;

IV - à quaisquer outros incentivos ou favores fiscais ou financeiro-fiscais, concedidos com base no Imposto de Circulação de Mercadorias, dos quais resulte redução ou eliminação, direta ou indireta, do respectivo ônus; [grifo não está no original]

$V$ - às prorrogações e às extensões das isenções vigentes nesta data.
\end{abstract}

Se por um lado o Art. $1^{0}$ enumera os pressupostos para a caracterização dos benefícios indevidos, o Art. $8^{\circ}$ preserve reações para afastar seus efeitos, quais sejam a nulidade do ato e ineficácia do crédito fiscal (Art. $8^{\circ}$, I, LC 24/75) e a exigibilidade do imposto não pago ou devolvido bem como "ineficácia da lei ou ato que concedeu remissão do débito correspondente" (Art. $8^{0}$, II, LC 24/75).

No plano da Lei Ordinária Estadual de n. 6.374/89-SP, no Art. 36, § 3 , observa-se 0 intento de se evitar efeitos da concessão indevida de incentivos fiscais mediante a glosa de créditos $^{9}$ de ICMS, fazendo com que contribuintes de São Paulo arquem com o tributo em sua integralidade caso a mercadoria tenha sido adquirida de fornecedor situado em Estado diverso e que pratique os benefícios mencionados.

0 ato normativo CAT de n. 36/2004 relaciona, em dois anexos, benefícios que sob sua perspectiva são considerados inconstitucionais. No Anexo I estão dispostos os incentivos contestados por meio de Ação Direta de Inconstitucionalidade. O Anexo II elenca 61 outros benefícios, classificados por Estado de origem de cada um deles, com a observação de que a

\footnotetext{
${ }^{9}$ Segundo 0 jargão fiscal, é a invalidação dos créditos relativos às operações anteriores (entradas), não mais podendo serem abatidos nas operações subseqüentes (saídas) - abatimentos que deveriam ocorrer em condições normais, corolários do preceito constitucional da não-cumulatividade.
} 
enumeração é meramente exemplificativa; o que suscita patente insegurança jurídica para o contribuinte.

Sob a perspectiva do contribuinte-adquirente, a glosa de créditos representa um custo adicional mesmo que haja redução do impacto fiscal na origem, pois este alívio repercute em pequena parcela no preço praticado pelo remetente, nunca na íntegra (PEIXOTO, 2005, p. 1.102). Ainda, um dos fundamentos levantados para a edição do Comunicado foi a preservação da livre concorrência. De fato, há um desequilíbrio gerado entre os fornecedores internos e os situados em outra unidade da Federação. No entanto, torna-se mais caro comprar de fornecedores situados em outros Estados do que de fornecedores internos então é de se esperar que aqueles passem a ser evitados. Ofende-se a livre-concorrência a pretexto de preservá-la (PEIXOTO, 2005, p. 1.103).

Afronta do mesmo modo os artigos 150, V e o 152, da CF/88, os quais vedam o estabelecimento de limitações ao tráfego de pessoas ou bens por meio de tributos interestaduais e intermunicipais; e qualquer tratamento diferenciado por parte dos Estados, Distrito Federal e Municípios de bens e serviços em razão de sua procedência ou destino.

É manifesto insulto aos primados da inalterabilidade e da privatividade da competência tributária, visto que se transpõe os limites da próprias prerrogativas e cobra-se imposto de competência alheia. Afinal, um Estado-membro não está habilitado a "proferir juízo de validade em relação às leis de outro Estado. Estão em posição de coordenação, não de hierarquia" (PEIXOTO, 2005, p. 1.106). Lesa o próprio pacto federativo e ainda o princípio da separação de funções, quando assume atribuições constitucionalmente reservadas ao Judiciário.

Outro recente litígio de difícil resolução é o travado entre os Estados do Amazonas e São Paulo. 0 CAT n. 36/2004 elenca em seu Anexo II a impossibilidade de aproveitamento de créditos oriundos da Zona Franca de Manaus, concedidos pelo Estado do Amazonas com fundamento na Lei de n. 2.826/2003 (regulada pelo Decreto n. 23.994/2003). Ocorre que os incentivos fiscais de ICMS relativos à Zona Franca de Manaus não se subordinam à sistemática dos convênios como reconhece a própria Lei Complementar n. 24/1975, em seu Art. 15:

Art. 15 - 0 disposto nesta Lei não se aplica às indústrias instaladas ou que vierem a instalar-se na Zona Franca de Manaus, sendo vedado às demais Unidades da Federação determinar a exclusão de incentivo fiscal, prêmio ou estímulo concedido pelo Estado do Amazonas. 
Em 1988, com o advento da atual Constituição Federal, a manutenção da Zona Franca de Manaus foi assegurada até 0 ano de 2013 (Art. 40, ADCT), tendo sido recentemente acrescentados mais 10 anos ao referido prazo, por força do disposto no Art. 92 do Ato das Disposições Constitucionais Transitórias, introduzido pela Emenda Constitucional n. 42/2003. Ao determinar que deva ser mantida tal "característica", o Constituinte reconheceu a "necessidade de haver continuidade de uma determinada qualidade da Zona Franca em si, que é a de ser objeto de um tratamento diferenciado em comparação com o dispensado a empreendimentos semelhantes em outras áreas do território brasileiro" (RAM OS FILHO, 2006, p. 8).

Mesmo ante o amparo legal dos subsídios fornecidos pelo Estado do Amazonas, a ADIN de n. 3350/SP impetrada pelo governo amazonense mal teve seu mérito apreciado pelo Supremo Tribunal Federal, sob a justificativa de que a ação direta de inconstitucionalidade é uma ferramenta para controle de atos normativos que ferem a Constituição Federal, enquanto o Comunicado em análise é apenas informativo, com o intuito de prestar esclarecimentos aos contribuintes paulistas. Não caberia, portanto, ADIN contra o Comunicado CAT 36/2004. A decisão é "consistente com o entendimento do STF acerca dos pressupostos formais da ADI[n]; inconsistente, contudo, com o tipo de resposta exigida pelo seu papel institucional" (PEIXOTO, 2005, p. 1.094).

Afora os diplomas acima especificados, destaca-se por sua relevância ao aludido tema a Lei de Responsabilidade Fiscal - LC de n. 101 de 04 de maio de 2000. Visando combater, conter ou disciplinar as concessões de incentivos ou benefícios de ordem tributária por meio de renúncia de receita, a lei especificou que tais renúncias serão somente possíveis quando acompanhadas de estimativa de impacto orçamentário-financeiro no exercício de sua vigência e nos dois seguintes, de tal modo que não vá influenciar as metas fiscais e acompanhada de medidas compensatórias no referido período.

Estabeleceu-se que somente será possível a concessão de benefícios tributários quando a receita estimada incorporar os efeitos da renúncia e houver a respectiva compensação com o aumento da receita, a qual poderá ocorrer por meio da elevação de alíquotas, ampliação da base de cálculo, majoração ou criação de tributo ou contribuição. É um caráter vinculado para a concessão, pois é preciso que se estime da renúncia da receita a compensação pela perda para criar uma situação de equilíbrio fiscal. 
A nova disciplina não impede, mas obsta parte dos abusos existentes na concessão dos incentivos e isenções, visto que condiciona à necessária compensação por meio do aumento de receita. Não abrange as vantagens concedidas de cunho patrimonial. É importante, todavia, para atribuir ao Tribunal de Contas eficácia no controle da legitimidade e economicidade nos casos de renúncia de receita, presente no Art. 70 da Constituição Federal. Deve-se analisar os incentivos estaduais segundo o critério da preservação das eficiências e no controle das ineficiências, necessários ao desenvolvimento harmônico e sustentável das regiões e Estados brasileiros.

Por fim, a guerra fiscal gera ineficiência econômica e o deslocamento improdutivo de mercadorias entre Estados. Em muitos casos, principalmente no comércio predatório do ramo atacadista, o benefício depende apenas do trânsito da mercadoria pelo Estado concedente do benefício, corroborando para o congestionamento da malha de transportes nacional.

\section{Conclusão}

Há autorização constitucional para a intervenção do Estado sobre o domínio econômico, nos termos do Art. 174 da CF. Esta possibilidade se justifica, exclusivamente, para implementar o Regime Jurídico-Econômico Constitucional prescrito, especialmente, no Art. $170 \mathrm{da} \mathrm{CF}$. Tratou-se nesta pesquisa sobre intervenção por meio de incentivos patrocinados pelos entes federados, com a finalidade de atrair investimentos privados para - Estado ou Município. Destacou-se o incentivo tributário e a preocupação com a denominada guerra fiscal. Pode-se afirmar diante dos argumentos apresentados, especialmente aquele que defende um federalismo de cooperação, que é possível qualificar tais iniciativas como uma concorrência desleal.

Enquanto não houver norma constitucional que discipline o tema fica fragilizado o princípio jurídico da segurança e da certeza do direito para as empresas que se utilizam destes incentivos. A necessidade desta norma constitucional supriria a discussão quanto à constitucionalidade das normas nacionais poderem ou não interferir na autonomia dos entes federados.

A eficiência dos incentivos fiscais destaca-se diante de outras modalidades de benefícios para o desenvolvimento regional ou local, entre eles, doações, investimentos em 
infra-estrutura, capacitação profissional. Constata-se, muitas vezes, que findo o prazo do benefício, as empresas buscam outras localidades (às vezes até outro país) para se instalarem, interrompendo o planejamento do Estado ou Município quanto ao seu desenvolvimento sócio-econômico.

Para que o incentivo tributário não venha causar prejuízo à arrecadação é preciso que a Lei de Responsabilidade Fiscal seja acionada, evitando-se o indevido uso político destes mecanismos. Este controle é fundamental, pois na seara econômica, entre os valores prestigiados tem-se os da eficiência e estabilidade e para que eles sejam concretizados os mecanismo jurídicos devem ser utilizados, exclusivamente, com fins de interesse público.

À luz das análises apresentadas conclui-se pela necessidade de reconfiguração do pacto federativo brasileiro. Os nocivos efeitos oriundos dessa competição desenfreada entre os Estados-membros e Municípios estão sendo paulatinamente sedimentados na prática cotidiana e constituem óbices quase que intransponíveis a uma célere e efetiva solução às desigualdades regionais e do cumprimento dos objetivos pretendidos pela Constituição.

\section{Referências}

ATALIBA, Geraldo. Hipóteses de incidência tributária. 6. ed. São Paulo: Malheiros, 2001.

BRASIL. M inistério do Planejamento, Orçamento e Gestão. Instituto Brasileiro de Geografia e Estatística. Perfil dos municípios brasileiros 2006, pesquisas de informações básicas municipais. Rio de Janeiro, 2007.

CRETELLA JÚNIOR, José. Comentários à constituição brasileira de 1988. Rio de Janeiro: Forense, 1993. v. 8.

DA SILVA, José Afonso. Curso de direito constitucional positivo. 19. ed., rev. e atual. São Paulo: Malheiros, 2001.

LOSS, Giovani R. A Guerra Fiscal e a Concorrência: a análise dos incentivos financeiros. Anais do XV Congresso Brasileiro de Direito Tributário. São Paulo: IDEPE - Instituto Geraldo Ataliba, 2002.

M ELLO, Oswaldo Aranha Bandeira de. Natureza jurídica do estado federal. São Paulo: Publicação da Prefeitura do M unicípio de São Paulo, 1948.

NOVOA, Cesar García. El principio de seguridad jurídica en materia tributaria. Madrid: M arcial Pons Ediciones Jurídicas y Sociales, S.A., 2000. 
PEIXOTO, Daniel Monteiro. Tributação no Setor Comercial: federação, competência tributária e guerra fiscal entre Estados via ICM S. São Paulo: Quartier Latin, 2005.

TIXIER, Gilbert; GEST, Guy. 0 Direito Fiscal Internacional. Trad. de Ana Rabaça. EuropaAmérica: Mem. Martins, 1986.

TRAM ONTIN, Odair. Incentivos públicos a empresas privadas \& guerra fiscal. Curitiba: Juruá, 2002. 